\title{
Ovarian follicle development in Booroola sheep exhibiting impaired bone morphogenetic protein signalling pathway
}

\author{
Chantelle Ruoss, Amanda Tadros, Tim O'Shea ${ }^{1}$, Jim McFarlane ${ }^{1}$ and Ghanim Almahbobi \\ School of Biomedical Sciences, Western Australian Biomedical Research Institute, Curtin Health Innovation \\ Research Institute, Curtin University of Technology, Kent Street, Bentley, Perth, Western Australia 6102, Australia and \\ ${ }^{1}$ Centre for Bioactive Discovery in Health and Aging, University of New England, Armidale, New South Wales 2351, \\ Australia
}

Correspondence should be addressed to G Almahbobi; Email: g.almahbobi@curtin.edu.au

\begin{abstract}
The role of bone morphogenetic proteins (BMPs) in the regulation of ovarian function has been extensively investigated but the mechanism of regulation is not well understood. The aim of this study was to investigate the effect of mutation in the BMP receptor in Booroola sheep on the number of primordial follicles and rate of follicle recruitment in comparison with that in normal merino sheep in vivo. Whole sheep ovaries at the time of birth, 1.5 and 5 years old were collected and processed for the follicle quantification, using computerised stereological methods and statistical analyses. At birth, the total number of primordial follicles in Booroola sheep was significantly lower than in merino sheep. At $\mathbf{1 . 5}$ and $\mathbf{5}$ years, a reversed pattern in favour of Booroola ewes was seen with significantly more primordial follicles than merino. In parallel, the rate of primordial follicle recruitment to developing cohort was substantially lower in Booroola ewes with only 51 and $66 \%$ of primordial follicle consumption at 1.5 and 5 years respectively compared to 92 and $97 \%$ in merino ewes. On other hand, the mean numbers of developing primary follicles were smaller in Booroola sheep at the time of birth, yet, Booroola ewes possess more primary follicles than merino at 1.5 years. These findings suggest that attenuation of the intraovarian signalling pathway of BMPs may in fact be a successful means of rationalising follicle consumption, preventing unnecessary loss of follicles from the initial primordial follicle pool, hence increasing reproductive longevity and fertility.

Reproduction (2009) 138 689-696
\end{abstract}

\section{Introduction}

During mammalian foetal development the female primordial germ cells (PGCs) are initially formed in the endodermal part of the yolk sac, migrate into the ovary and develop into oocytes which then become parts of primordial follicles. Females are endowed with a finite number of primordial follicles that develop by folliculogenesis. Ovarian folliculogenesis is a continuing physiological process whereby development and maturation of follicles occur via a series of stages, propelling the follicle towards steroid hormone production and ovulation (Shimasaki et al. 2004, Knight \& Glister 2006). Follicles progress through primordial, primary, preantral, antral Graafian and mature preovulatory stages with the initial transition from primordial to primary follicle is also known as follicle recruitment (Lee et al. 2001, Thomas \& Vanderhyden 2006). Folliculogenesis operates mainly under the control of gonadotrophins (FSH and $\mathrm{LH}$ ) regulated by the hypothalamic-pituitary-gonadal axis (Fauser \& Van Heusden 1997), excluding the initial stage of follicle recruitment, which functions independently of these gonadotrophins (Lee et al. 2001).
Primordial follicles are arrested at this stage and can stay viable until the end of reproductive longevity. Once recruited into the primary stage, follicles either complete maturation and ovulate, or die via atresia (Lee et al. 2001, Knight \& Glister 2003). As a result, the follicular reserve continually declines throughout life particularly after the initiation of ovarian cycling (Broekmans et al. 2007). Repetition of ovulation and atresia with age results in complete depletion of germ cells leading to menopause in women, and the end of reproductive period in mammals, both signalled by cessation of ovarian function.

Research has shown a role for $\sim 20$ bone morphogenetic proteins (BMPs; Knight \& Glister 2003) in several processes, including the formation of PGCs during foetal development in mice (Shimasaki et al. 1999, 2004), follicle recruitment in cultured rat ovaries (Nilsson \& Skinner 2003) and steroidogenic and ovulatory processes in rats (Shimasaki et al. 1999). More recently, the role of BMP4 in the recruitment of mouse primordial follicles has been confirmed in vivo (Tanwar et al. 2008). BMPs signal via two BMP receptors (BMPR), type I, and type II (Chang et al. 2001), 
type I comprising BMPR1A and BMPR1B (Chang et al. 2002, Shimasaki et al. 2004). In situ hybridisation showed that Bmp4 mRNA is produced by the theca cells of rats while $B m p r$ is localised in the granulosa cells, indicating a paracrine action (Shimasaki et al. 1999).

Booroola sheep, a strain with a natural point mutation in the highly conserved intracellular serine threonine kinase signalling domain of the BMPR1B (Wilson et al. 2001, Shimasaki et al. 2004, Campbell et al. 2006), show a significant increase in ovulation rate. However, it has not yet been determined whether the increased ovulation rate in Booroola sheep is due to reduced atresia of follicles, enhanced follicular maturation or more specifically increased follicular recruitment. The proposed mechanisms relate to evidence that granulosa cells of Booroola ewes are less sensitive to the inhibitory action of BMPs on progesterone synthesis (Shimasaki et al. 2004). This results in follicles that mature smaller in size, higher concentrations of FSH during the oestrous cycle and increased progesterone production during the luteal phase of the cycle (McNatty et al. 1989, Xia et al. 2003). This results in increased progesterone production in turn, promoting ovulation rate and litter size (Shimasaki et al. 2004). Recently, it has been reported that increased expression of BMPR1B in Yunling black goat was correlated with a lower number of follicles and smaller litter size, a case supportive of the Booroola model (Cui et al. 2009).

It appears that BMPs normally exert a dual function, promoting PGC formation, primordial follicle recruitment and oestradiol production during early follicular stages, while reducing progesterone formation and delaying ovulation during later follicular stages (Lawson et al. 1999, Shimasaki et al. 1999, Nilsson \& Skinner 2003). We propose that attenuation of BMPs' action may lead to a reduction in the rate of follicle recruitment, thereby rationalising the usage of primordial follicles from the reserve pool. Two studies in particular attempted to investigate the underlying mechanisms of high fecundity rate in Booroola sheep, focussing on follicular numbers and recruitment (Driancourt et al. 1985, Smith et al. 1994). However, the largely conflicting results reported by these two studies necessitate further research.

The current study aims to investigate the effect of BMP impaired signalling pathway, due to BMPR mutation, on primordial follicle formation and rate of recruitment in Booroola sheep, partly with intent to resolve previously conflicting results. Specifically, the current study aimed to quantify the initial number of primordial follicles at the time of birth of Booroola lambs and compare this with control merino lambs, utilising computerised stereological analysis (Gundersen et al. 1988). Furthermore, the rate of follicular recruitment was investigated by analysing numbers of primordial and primary follicles and correlating this with the age of the animals. The overall results suggest that the impaired signalling pathway due to mutation of BMPR in Booroola ewes may be an important factor regulating folliculogenesis and prolonging the reproductive period in females.

\section{Results \\ Ovulation rates and progesterone levels}

At both 1.5 and 5 years of age the ovulation rate was significantly $(P<0.05)$ higher in the Booroola ewes compared to the merino ewes (Fig. 1). In addition, ovulation rate was significantly $(P<0.05)$ higher in the older (5 years) Booroola ewes compared to the maiden age ewes (1.5 years) of the same strain.

However, the circulating concentrations of progesterone were not significantly different between strains regardless of age except in 5-year-old Booroola ewes at early stage of oestrous cycle where progesterone was significantly $(P<0.05)$ higher than in merino sheep (Fig. 2).

\section{Stereological quantification of follicles in sheep ovaries}

Regardless of animal strain, the overall mean values of absolute number of primordial and primary follicles per ovary decreased with age with much pronounced reduction in numbers in 1.5 years of age (Figs 3 and 4). Only $\sim 10 \%$ of the primordial follicles found in merino ewes at birth were left in the ovaries of 1.5 years merino sheep and this was further decreased to only $4.5 \%$ in ovaries of 5 -year-old ewes. In contrast, $50 \%$ of the primordial follicles found in Booroola ewes at birth were left in the ovaries of 1.5-year-old Booroola ewes and this was only marginally decreased to one-third at the age of 5 years. Similarly, the numbers of primary follicles found in ovaries of 1.5-year-old ewes were

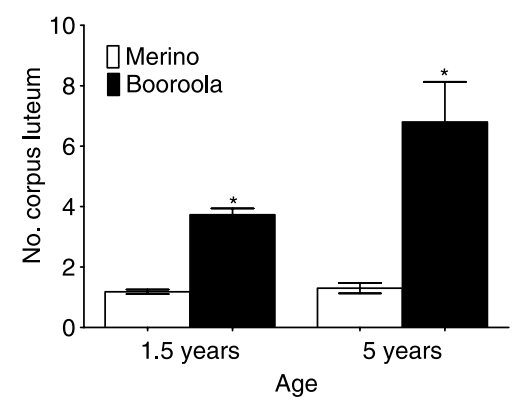

Figure 1 Ovulation rates in sheep strains at different age. The rate of ovulation was determined by counting the number of corpora lutea over two oestrus cycles using laparoscopy. The numbers of corpora lutea were significantly $\left({ }^{*} P<0.05\right)$ higher in Booroola (solid bars) ewes than merinos (open bars) at 1.5 and 5 years of age. The rate of ovulation, reflected by the numbers of corpora lutea was even more pronounced $(* P<0.05)$ in older ( 5 years) ewes than in 1.5 years of age. ( $n=5$ ewes/group). 


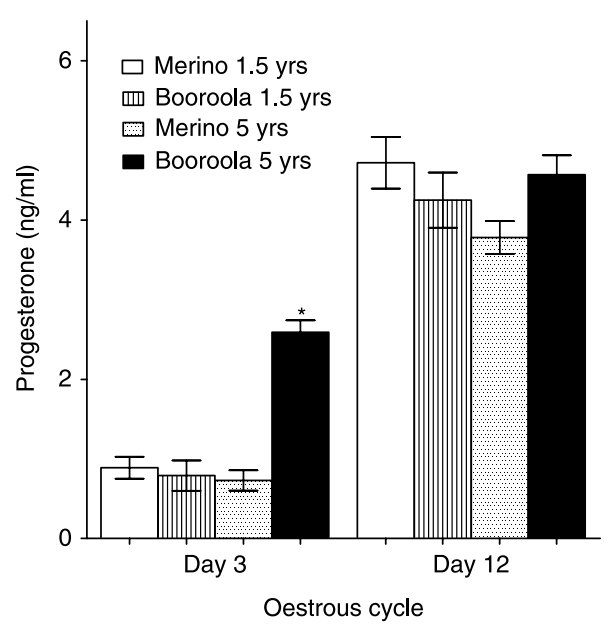

Figure 2 Progesterone levels in sheep strains at different age. Progesterone was measured in jugular blood samples using in house RIA. Except in older (5 years) Booroola (solid bars) ewes during the early stage (day 3 ) of oestrous cycle the levels of circulating progesterone showed no significant change irrespective of different animal strains and days of oestrous cycle. Individual data represents a mean \pm s.D. of two samples. The intra- and inter-assay variations were 4 and $11 \%$ respectively. ${ }^{*} P<0.05$ ( $n=5$ ewes/group).

29 and $60 \%$ of those found in ovaries of merino and Booroola ewes at birth respectively. Clearly, the high rate of follicle loss occurs during the first 18 months of age particularly in merino strain (Figs 3 and 4).

Analysis of the ratio of mean values of absolute number of primordial follicles in Booroola ewes relative to follicles in merino ewes was performed. As shown in Table 1, the mean total number of primordial follicles in Booroola strain was only $36 \%$ of that present in merino strain at the time of birth. However, this ratio became reversed at 1.5 and 5 years of age whereby the mean total numbers of primordial follicles in Booroola strain was 207 and $367 \%$ of that in merino strain respectively (Table 1 ).

Non-parametric test analysis showed that the total number of primordial follicles in Booroola lambs $(n=6)$ at birth was significantly $(P=0.008)$ lower than in merino of the same age $(n=6$; Fig. 3). More interestingly, a considerable reversal of proportion in the number of primordial follicles occurs in 1.5 -year-old whereby a significantly $(P=0.027)$ larger number of primordial follicles was observed in Booroola ewes $(n=5)$ when compared with number of follicles in merino ewes $(n=5$; Fig. 3). The large number of primordial follicles in favour of Booroola ewes was more pronounced at 5 years of age $(P=0.003$; Booroola $n=5$ and merino $n=4)$. This clearly showed that primordial follicle recruitment is substantially lower in Booroola ewes compared with that in merino, as reflected by the difference in the number of primordial follicles remaining between newborn and 1.5 and 5-year-old Booroola and merino ewes (Fig. 3).
Utilising the mean values of absolute numbers of primordial follicles, the ratios of primordial follicle consumption/loss were determined. As shown in Table 2, only $51 \%$ of primordial follicles disappeared in Booroola ovaries at 1.5 years, while in merino ewes, $92 \%$ of primordial follicles were lost (Table 2). At 5 years of age, $66 \%$ of primordial follicles were used in Booroola ewes in comparison with $97 \%$ of primordial follicles consumed in merino ewes.

Similar to the case of primordial follicles, Table 3 shows that the ratio of the mean total number of primary follicles in Booroola strain was $58 \%$ of that present in merino strain at the time of birth but again this ratio was reversed in favour of Booroola ewes to become $290 \%$ at 1.5 years of age (Table 3 ).

Analysis of the mean values of absolute numbers of primary follicles showed that in Booroola ewes, the ratio of primary follicles present at 1.5 years was equal to $76 \%$ of the primary follicle number present at birth, while in the merino ewes, only $15 \%$ of primary follicles present at birth were found at 1.5 years (Table 3 ).

Non-parametric test analysis of these data showed that the mean number of primary follicles per ovary in newborn Booroola animals $(n=5)$ was less than in merino ewes ( $n=6$; Fig. 4). In contrast, a reverse proportion was observed at 1.5 years when Booroola ewes $(n=3)$ showed more primary follicles than merino sheep $(n=3)$. However, these observations were trend and not statistically significant (Fig. 4).

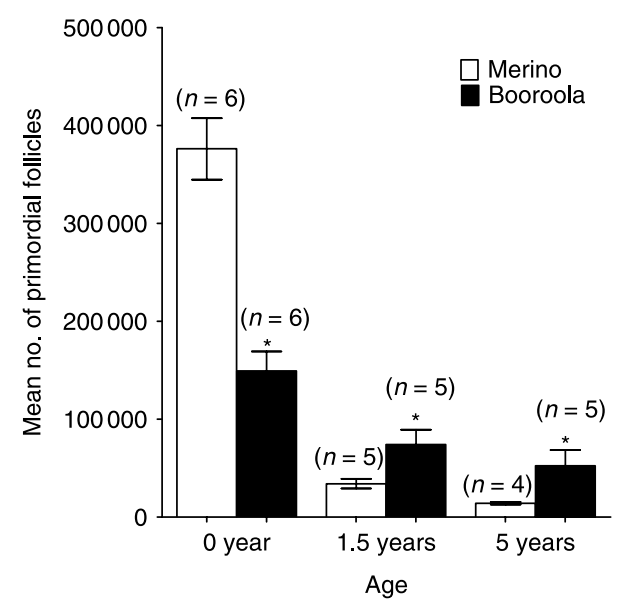

Figure 3 Number of primordial follicles in sheep strains at different age. The absolute follicle number per ovary was calculated in every one-hundredth serial section of individual ovary using computerised stereological method. The mean \pm s.D. of absolute number of primordial follicles per ovary was significantly $(* P=0.008)$ lower in Booroola (solid bars) ewes compared with merino (open bars) ewes at the time of birth (0 year). At 1.5 and 5 years, a reversed trend was observed in favor of Booroola strain than merino strain. At 1.5 and 5 years of age, Booroola ewes have significantly $(* P=0.027$ and $P=0.003$ respectively) increased number of primordial follicles when compared with merino strain. ( $n$, number of ewes). 


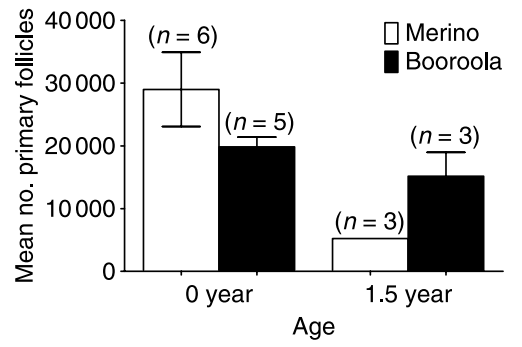

Figure 4 Number of primary follicles in sheep strains at different age. The absolute follicle number per ovary was calculated in every one-hundredth serial section of individual ovary using computerised stereological method. While the mean \pm s.D. of absolute numbers of the primary follicles in Booroola (solid bars) ewes were lower than in merino (open bars) strain at birth, this trend was reversed at 1.5 years, when Booroola ewes contains substantially more primary follicles than merino ewes. Although the number of primary follicles in 1.5-year-old Booroola ewes showed substantial increase, this difference was not statistically significant probably due to small numbers of ovaries. ( $n$, number of ewes).

\section{Discussion}

The role of BMPs in the regulation of ovarian function has been previously investigated predominantly in rodent models using various in vitro experimental set-ups including cell culture (Shimasaki et al. 2004), Bmp $4^{\text {lacZneo }}$ haplo-insufficient mice (Lawson et al. 1999) and cultured whole ovaries (Nilsson \& Skinner 2003). This current study describes how the mutation in BMPR1B may be responsible for altering the formation of primordial follicles and the rate of follicle recruitment in mutant Booroola sheep in vivo, an appropriate model to investigate the role of BMPs in the regulation of ovarian function (Tanwar et al. 2008).

Regardless of strain, newborn ewes possess a significantly greater number of primordial and primary follicles than ewes at 1.5 and 5 years. Follicle recruitment and atresia, may explain this difference in number as depletion begins during foetal development and continues until complete follicular exhaustion (Picton 2000). The far greatest loss in primordial follicles occurs during the first 18 months of age, a similar observation has been reported in mice when the largest number of primordial follicles is recruited during the first 2 weeks after birth (Pedersen \& Peters 1971,
Elvin \& Matzuk 1998, Kerr et al. 2006). These results in sheep fail to support the hypothesis of postnatal renewal of primordial follicles in mice (Johnson et al. 2004, Kerr et al. 2006).

More interestingly, newborn Booroola sheep possess significantly fewer primordial follicles than merino sheep of the same age. These results are logically expected based on previous research implicating BMPs in the formation of PGCs in mice (Lawson et al. 1999). As Booroola sheep possess the BMPR mutation, resulting in partial loss of BMP signalling, the ability of these animals to produce PGCs is impaired.

However, at 1.5 and 5 years the proportion of primordial to primary follicles in Booroola ewes versus merinos was significantly reversed. These results suggest that Booroola ewes experience a decreased rate of follicle recruitment, supporting previous research in rodents (Nilsson \& Skinner 2003, Tanwar et al. 2008) but contradicting results by Smith et al. (1994) in sheep. In contrast to several other reports (Lawson et al. 1999, Nilsson \& Skinner 2003, Shimasaki et al. 2004), Smith et al. described the presence of more primordial follicles, yet fewer growing follicles in Booroola foetuses, concluding that Booroola sheep experience a reduced rate of follicle recruitment. On other hand, research conducted by Driancourt et al. (1985) described the presence of fewer primordial follicles in 3 - and 4-year-old Booroola ewes compared with merino ewes, suggesting a greater intensity of follicle recruitment in the Booroola ewes.

This obvious discrepancy in analysis and conclusion between the previous studies on one hand and previous studies and present data on the other hand is difficult to interpret taking into consideration the many possible variables that may affect the outcome. As an example of these variables and different to previous reports, we have used new computerised stereological methods to estimate follicular numbers (Myers et al. 2004, Charleston et al. 2007). Also, we have investigated the numbers of follicles in several points of age allowing more accurate analysis of follicle dynamic and resulting conclusion. For example, the presence of fewer primordial follicles in 3- and 4-year-old sheep (Driancourt et al. 1985) does not necessarily reflect a greater rate of follicle recruitment without comparison with the initial starting numbers at birth. In this regard,

Table 1 Numbers and ratios of primordial follicles in sheep strains at different age.

\begin{tabular}{|c|c|c|c|c|c|c|}
\hline \multirow[b]{2}{*}{ Age } & \multicolumn{2}{|l|}{ Newborn } & \multicolumn{2}{|l|}{1.5 years } & \multicolumn{2}{|l|}{5 years } \\
\hline & Mean absolute number & Ratio \% B:M & Mean absolute number & Ratio \% B:M & Mean absolute number & Ratio \% B:M \\
\hline Booroola (B) & $152206(n=6)$ & $36 \%$ & $74121(n=5)$ & $207 \%$ & $50345(n=5)$ & $357 \%$ \\
\hline Merino (M) & $426133(n=6)$ & & $35762(n=4)$ & & $14108(n=5)$ & \\
\hline
\end{tabular}

Ratios of mean absolute numbers of primordial follicles in Booroola as percentages of those in merino ewes at birth (36\%), 1.5 years (207\%) and 5 years $(357 \%)$ of age. Despite the low ratio of primordial follicles in Booroola ewes at birth the ratio was significantly increased with age, indicating significantly low rate of follicle consumption in Booroola ewes. $n$, number of ewes. 
Table 2 Primordial follicle consumption in sheep strains at different age.

\begin{tabular}{lcc}
\hline \multirow{2}{*}{ Strain } & \multicolumn{2}{c}{ Rates of primordial follicle consumption } \\
\cline { 2 - 3 } & At 1.5 years & At 5 years \\
\hline Booroola & $51 \%(n=5)$ & $67 \%(n=5)$ \\
Merino & $92 \%(n=5)$ & $97 \%(n=4)$ \\
\hline
\end{tabular}

Rates of primordial follicle consumption at 1.5 and 5 years, calculated as proportional to numbers of primordial follicles at birth of the same animal strain. The rates of follicle consumption were significantly higher in merino sheep (92 and 97\%) than in Booroola (51 and 67\%) at both ages respectively. $n$, number of ewes.

this study has provided a stronger indication of a lower rate of follicle recruitment in Booroola ewes based on the number of primordial follicles remaining in ovaries of 1.5- and 5-year-old ewes comparing with those in newborn ewes. The effect was very significant leading to a complete reversal of follicle proportions in favour of Booroola ewes after 1.5 year of the postnatal life.

A similar but less significant pattern was seen in the numbers of primary follicles. At 1.5 years of age more primary follicles were counted in ovaries of Booroola ewes, although fewer primary follicles were counted at birth, suggesting increased follicle survival or reduced atresia in these animals, a process that begins during foetal development and continues until complete exhaustion of follicular pool (Fauser \& Van Heusden 1997, Picton 2000, Knight \& Glister 2006, Broekmans et al. 2007). It would therefore be interesting to address this issue in further studies.

Interestingly, despite the possible slowing of follicular recruitment in Booroola ewes, ovulation rate was significantly higher than in merino ewes (Campbell et al. 2006). Consequently, litter size is also affected with each copy of the FECB gene increasing litter size by one to two extra lambs (Wilson et al. 2001). In support of this, a precocious increased in progesterone formation was observed in Booroola at day 3 of oestrous cycle. As BMPs normally cause decreased progesterone production (Shimasaki et al. 1999, 2004), it appears that reduced BMP signaling in Booroola ewes underlies the increased levels of progesterone, and FSH therefore promoting follicular maturation and ultimately rate of ovulation observed in this study. In previous study we (G A) have demonstrated that ultrastructural luteinisation of granulosa cells of preovulatory follicles in mares coincides with elevation of progesterone production (Silberzahn et al. 1985).

Overall, this study has resolved previous conflicting research, confirming that newborn Booroola sheep in fact start with fewer primordial follicles, confirming the pivotal role of BMPs in the formation of PGCs. The reversed proportions observed in the number of primordial and primary follicles between Booroola and merino ewes indicate that the rate of recruitment of follicles in Booroola ewes is slower than that seen in the merinos. These results support the notion that BMPs exert dual functions within the ovary, potentially increasing rate of PGC formation and follicle recruitment, while also inhibiting progesterone formation and follicular maturation required for ovulation. BMPs also clearly have a role in the pituitary regulating gonadotrophin release particularly FSH (McNatty et al. 1989, Xia et al. 2003), thus when BMP signalling is attenuated FSH concentrations rise. This in turn stimulates a precocious maturation of multiple smaller follicles, hence multiple ovulation. In contrast, increased expression of BMPR1B in Yunling black goat was correlated with small numbers of maturing follicles and litter size (Cui et al. 2009).

These results provide fundamental information that may contribute to further research implicating BMPs as a tool to control follicle recruitment by the regulation of intraovarian BMPs expression and/or function, mimicking Booroola model. Such approach may prove useful for rationalising consumption of follicles and thereby ultimately extending the reproductive lifespan and hence improving fertility. In addition, this knowledge may assist in clinical applications such as IVF as an alternative to fertility drugs that are commonly used to promote follicle maturation.

\section{Materials and Methods}

\section{Sheep and sample collection}

Sheep were housed in open paddocks at the University of New England. The ewes were synchronised using vaginal sponges (Ovagest, Bionich Animal Health, Armidale, NSW, Australia) and joined with vasectomised rams harnessed with marking crayons to determine the onset of oestrous. Jugular blood samples were collected daily over two oestrous cycles

Table 3 Numbers and ratios of primary follicles in sheep strains at different age.

\begin{tabular}{|c|c|c|c|c|c|}
\hline \multirow[b]{2}{*}{ Age } & \multicolumn{2}{|c|}{ Newborn } & \multicolumn{3}{|c|}{1.5 years } \\
\hline & Mean absolute number & Ratio \% B:M & Mean absolute number & Ratio \% B:M & Ratio \% of survival \\
\hline $\begin{array}{l}\text { Booroola } \\
\text { Merino }\end{array}$ & $\begin{array}{l}19836(n=5) \\
34378(n=6)\end{array}$ & $58 \%$ & $\begin{array}{r}15170(n=3) \\
5240(n=3)\end{array}$ & $290 \%$ & $\begin{array}{l}76 \% \\
15 \%\end{array}$ \\
\hline
\end{tabular}

Ratios of mean absolute numbers of primary follicles in Booroola ewes as percentages of those in merino ewes at a given age and percentages of primary follicle survival at 1.5 years. While low ratio was seen at birth $(58 \%)$, this was significantly increased at 1.5 years $(290 \%)$, as reflected by the high rate of follicle survival in Booroola ewes $(76 \%)$ when compared with that in merino ewes $(15 \%) . n$, number of ewes. 

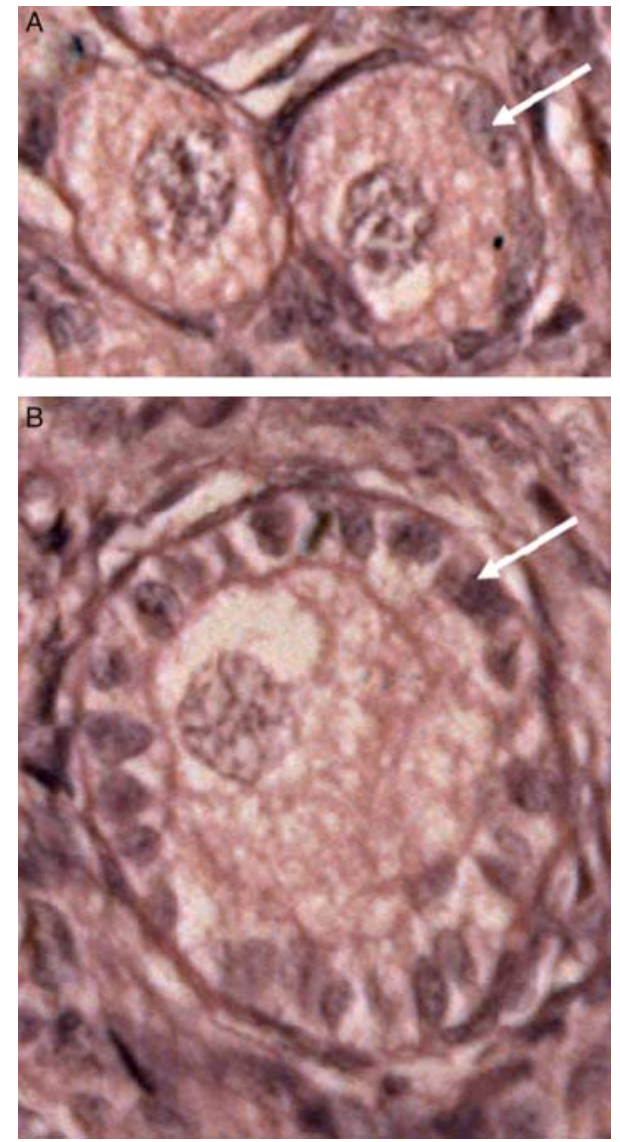

Figure 5 Histology of follicles. Ovarian sections $(4 \mu \mathrm{m})$ were examined under light microscope to identify the different types of follicles.

(A) Primordial follicles show oocytes partially or completely enclosed by flattened squamous follicular cells (arrow). (B) Enlarged primary follicle shows an oocyte surrounded by a complete layer of cuboidal granulosa cells (arrow). Original magnification $500 \times$.

and just before ovariectomy and stored at $-20{ }^{\circ} \mathrm{C}$ for progesterone measurement. Ovulation rate, expressed by the number of corpora lutea was determined over two oestrous cycles using laparoscopy. On the third cycle the ovaries were removed via bilateral ovariectomy while sheep were under general anaesthesia. Whole ovaries from Booroola and merino sheep at birth ( $n=6$ per strain), 1.5 years of age $(n=5$ per strain) and 5 years of age $(n=5$ per strain) were obtained. All experimentation was approved by the animal ethics committee, University of New England, Armidale, NSW, Australia.

\section{Ovaries and histology}

One ovary of each animal used for this study was dissected to remove excess surrounding tissue before they were fixed in Bouin's fixative, embedded in paraffin blocks and processed for histological study. Serial sections were exhaustively cut at $4 \mu \mathrm{m}$ throughout the whole ovary using a rotary microtome. The sections were consecutively labelled and mounted on glass slides and stained with haematoxylin and eosin. Follicular stages were identified using light microscopy as either primordial (Fig. 5A) or primary (Fig. 5B) as previously described (Myers et al. 2004). Briefly, primordial follicles were identified as consisting of an oocyte partially or completely enclosed by flattened squamous follicular cells, while primary follicles were those consisting of an oocyte surrounded by a complete layer of cuboidal granulosa cells (Kezele \& Skinner 2003, Juengel et al. 2004, Shimasaki et al. 2004, Skinner 2005, Thomas \& Vanderhyden 2006). Follicle size and the presence of a zona pellucida were also used as means of primary follicle identification.

\section{RIA of progesterone}

Progesterone was measured in two jugular samples of each day of the cycle and the jugular samples just before surgery. The assay was performed using a similar procedure to that was described by Xia et al. (2003). Briefly, the antiserum was
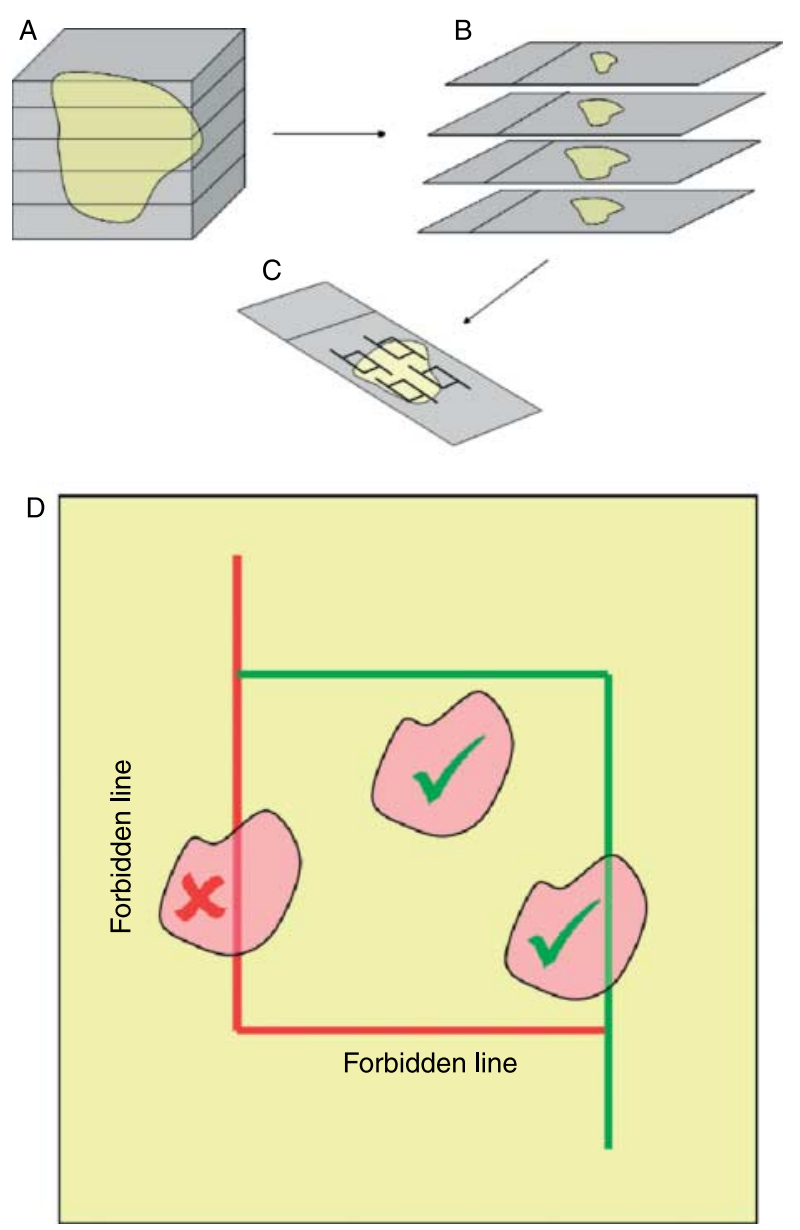

Figure 6 Nomination, placement of sampling sites and follicle counting by stereological analysis. (A) Whole embedded ovaries were exhaustively sectioned at $4 \mu \mathrm{m}$ using a rotary microtome. (B) Every onehundredth section (a total of $400 \mu \mathrm{m}$ intervals) was taken for stereological analysis. (C) A number of counting frames were randomly placed within the outlined area of the tissue via the Stereo Investigator software. (D) Each counting frame used to count numbers of primordial and primary follicles consisted of two contiguous forbidden lines (red). Any follicle falling within the counting frame and not intersecting these two forbidden lines was counted, while others were not counted. 
prepared using progesterone-11 $\alpha$-HS-BSA (\#230, Bioquest Ltd, North Ryde, NSW, Australia). Each sample was extracted in duplicate with a 10 times volume of diethyl ether. The sensitivity of the assay was $0.025 \mathrm{ng} / \mathrm{ml}$. The intra-assay variation was $4 \%$ and the inter-assay variation was $11 \%$.

\section{Stereology of ovarian follicles}

Follicle number per ovary was calculated using computerised stereological methods (Stereo Investigator Software Version 7; MicroBrightField Inc., Colchester, MA, USA). Initially, every one-hundredth section (400 $\mu \mathrm{m}$ gap) was selected in the order generated via microtomy, providing unbiased representation of the whole ovary. These sections were then analysed using established stereology techniques based on the method originally described by Gundersen et al. (1988) with slight modifications. An outline of the entire ovarian section was determined under low magnification using objective lens $4 \times$ to indicate restricted sampling areas and therefore placement of counting frames. The counting frames consisted of a counting square possessing two contiguous forbidden lines (Fig. 6). Only objects (follicles) falling within the counting square and not intersecting these forbidden lines were counted. Sampling sites (placement of counting frames) were randomly selected according to the Stereo Investigator software, with a range of 13-26 sites in samples from newborn animals and 40-75 in samples from 1.5- and 5-year-old animals.

Absolute number was estimated via the Fractionator method according to the manufacturer's guidelines. The fractionator is a stereological method commonly used for systematic sampling of a region of interest that is otherwise too large to count in its entirety, in this study, the whole ovary. Structures of interest, in this case the number of primordial or primary follicles, are directly counted within a known fraction of the original structure. The counts generated from this procedure are then multiplied by the reciprocal of the fraction sampled (Gundersen et al. 1988, West 1999, Charleston et al. 2007).

The above method of follicle counting is recommended as a stringent requirement for obtaining better estimates of the total numbers of follicles per ovary as increasing the number of examined sections (for example every fiftieth section) will minimise the efficiency of stereological estimation in favour of manual counting. However, examination of fewer sections (every one-hundredth section, $400 \mu \mathrm{m}$ ) may reduce the probability of finding follicles within the right position of the counting frames, as described above. This is particularly critical when counting a relatively small number and/or size $(100-200 \mu \mathrm{m})$ of follicles such as in the case of primary follicles in 5-year-old ewes. As a result, in certain ovaries of older animals we could not count any primary and to a lesser degree primordial follicles within the counting frames, although similar follicles existed in the same sections but not in the right location for counting. To avoid the underestimation of follicle numbers in such sets of samples these ovaries with no counted follicles were not included in the $n$-values for further analysis. Such a measure has further increased the accuracy and significance of our results.

\section{Statistical analysis}

Statistical analyses were performed using JMP 6 statistical package (2005; SAS Institute Inc., Cary, NC, USA). For an initial overview of the data, tree regression models (Breiman et al. 1984) were fitted for both the follicles and hormones data and response variables were follicular number and hormone concentrations. The tree building was stopped at a maximum of 20 terminal nodes, and constrained so that all nodes contained a minimum of 10 cases. Covariates used to build the tree were type and age of the sheep or hormone concentration, forming the basis of subsequent parametric modelling. A general linear model was used to describe the relationship between sheep type and age, with the response variable, follicle type. The models were examined and the residuals plotted. They were found to be heteroskedastic; therefore, subsequent analyses were done on log-transformed data. Statistical significance was accepted at $P \leq 0.05$.

\section{Declaration of interest}

There is no conflict of interest that could be perceived as prejudicing the impartiality of this research.

\section{Funding}

This research did not receive any specific grant from any funding agency in the public, commercial or not-for-profit sector.

\section{Acknowledgements}

The authors are grateful to Dr Damien Hewitt, Dr George Newland, Long Vo and Karl Fairhurst for their assistance with the stereological, statistical analyses, figure preparation and histology guidance respectively. The authors would like to thank Mike Slavin of the Histology Department at Murdoch University for his help in processing all sheep samples, and Guy Ben-Ary of The University of Western Australia for his assistance with the stereological training.

\section{References}

Breiman I, Friedman JH, Olshen RA \& Stone CJ 1984 Classification and Regression Trees. Pacific Grove: Wadsworth.

Broekmans FJ, Knauff EAH, Te Velde ER, Macklon NS \& Fauser BC 2007 Female reproductive ageing: current knowledge and future trends. Trends in Endocrinology and Metabolism 18 58-65.

Campbell BK, Souza CJH, Skinner AJ, Webb R \& Baird DT 2006 Enhanced response of granulosa and theca cells from sheep carriers of the FecB mutation in vitro to gonadotrophinns and bone morphogenetic protein-2, -4 and -6. Endocrinology 147 1608-1620.

Chang H, Lau AL \& Matzuk MM 2001 Studying TGF- $\beta$ superfamily signaling by knockouts and knockins. Molecular and Cellular Endocrinology 180 39-46.

Chang H, Brown CW \& Matzuk MM 2002 Genetic analysis of the mammalian transforming growth factor- $\beta$ superfamily. Endocrine Reviews 23 787-823.

Charleston JS, Hansen KR, Thyer AC, Charleston LB, Gougeon A, Siebert JR, Soules MR \& Klein NA 2007 Estimating human ovarian non-growing follicle number: the application of modern stereology techniques to an old problem. Human Reproduction 22 2103-2110. 
Cui HX, Zhao SM, Cheng ML, Guo L, Ye RQ, Liu WQ \& Gao SZ 2009 Cloning and expression levels of genes relating to the ovulation rate of the Yunling black goat. Biology of Reproduction $80219-226$.

Driancourt MA, Cahill LP \& Bindon BM 1985 Ovarian follicular populations and preovulatory enlargement in Booroola and control merino ewes. Journal of Reproduction and Fertility 73 93-107.

Elvin JA \& Matzuk MM 1998 Mouse models of ovarian failure. Reviews of Reproduction 3 183-195.

Fauser BC \& Van Heusden AM 1997 Manipulation of human ovarian function: physiological concepts and clinical consequences. Endocrine Reviews 1871.

Gundersen J, Bagger T, Bendtsen S, Evans S, Korbo L, Marcussen NA, Nielsen K, Nyengaad J \& Pakkenberg B 1988 The new stereological tools: disector, fractionator, nucleator and point sampled intercepts and their use in pathological research and diagnosis. Acta Pathologica, Microbiologica, et Immunologica Scandinavica 96 857-881.

Johnson J, Canning J, Kaneko T, Pru JK \& Tilly JL 2004 Germline stem cells and follicular renewal in the postnatal mammalian ovary. Nature $\mathbf{4 2 8}$ 145-150.

Juengel JL, Bibby AH, Reader KL, Lun S, Quirke LD, Haydon LJ \& Mcnatty KP 2004 The role of transforming growth factor-beta (TGF-beta) during ovarian follicular development in sheep. Reproductive Biology and Endocrinology 278.

Kerr JB, Duckett R, Myers M, Britt KL, Mladenovska T \& Findlay JK 2006 Quantification of healthy follicles in the neonatal and adult mouse ovary: evidence for maintenance of primordial follicle supply. Reproduction 132 95-109.

Kezele P \& Skinner MK 2003 Regulation of ovarian primordial follicle assembly and development of oestrogen and progesterone: endocrine model of follicle assembly. Endocrinology 144 3329-3337.

Knight PG \& Glister C 2003 Local roles of TGF- $\beta$ superfamily members in the control of ovarian follicle development. Animal Reproduction Science 78 165-183.

Knight PG \& Glister C 2006 TGF- $\beta$ superfamily members and ovarian follicle development. Reproduction 132 191-206.

Lawson KA, Dunn NR, Roelen BA, Zeinstra LM, Davis AM, Wright CV, Korving JP \& Hogan BL 1999 Bmp4 is required for the generation of primordial germ cells in the mouse embryo. Genes and Development 13 424-436.

Lee WS, Otsuka F, Moore RK \& Shimasaki S 2001 Effect of bone morphogenetic protein-7 on folliculogenesis and ovulation in the rat. Biology of Reproduction 65 994-999.

McNatty KP, Fisher M, Collins F, Hudson NL, Heath DA, Ball K \& Henderson KM 1989 Differences in the plasma concentrations of $\mathrm{FSH}$ and $\mathrm{LH}$ in ovariectomized Booroola $\mathrm{FF}$ and ++ ewes. Journal of Reproduction and Fertility 85 705-713.

Myers M, Britt K, Wreford N, Ebling F \& Kerr J 2004 Methods for quantifying follicular numbers within the mouse ovary. Reproduction 127 569-580.
Nilsson EE \& skinner MK 2003 Bone morphogenetic protein-4 acts as an ovarian follicle survival factor and promotes primordial follicle development. Biology of Reproduction 69 1265-1272.

Pedersen T \& Peters H 1971 Follicle growth and cell dynamics in the mouse ovary during pregnancy. Fertility and Sterility 22 42-52.

Picton HM 2000 Activation of follicle development: the primordial follicle. Theriogenology 55 1193-1210.

Shimasaki S, Zachow RJ, Li D, Kim H, Iemura SI, Ueno N, Sampath K, Chang RJ \& Erickson GF 1999 A functional bone morphogenetic protein system in the ovary. PNAS $967282-7287$.

Shimasaki S, Moore RK, Otsuka F \& Erickson GF 2004 The bone morphogenetic protein system in mammalian reproduction. Endocrine Reviews 25 71-101.

Silberzahn P, Almahbobi G, Dehnnin L \& Merouane A 1985 Estrogen metabolites in equine ovarian follicles: gas chromatographic-mass spectrometric determination in relation to follicular ultrastructure and progestin content. Journal of Steroid Biochemistry 22 501-505.

Skinner MK 2005 Regulation of primordial follicle assembly and development. Human Reproduction Update 11 461-471.

Smith P, Braw-tal R, Corrigan K, Hudson NL, Heath DA \& Mcnatty KP 1994 Ontogeny of ovarian follicle development in Booroola sheep fetuses that are homozygous carriers or non-carriers of the FecB gene. Journal of Reproduction and Fertility 100 485-490.

Tanwar PS, O'Shea T \& McFarlane JR 2008 In vivo evidence for role of bone morphogenetic protein 4 in the mouse ovary. Animal Reproduction Science 106 232-240.

Thomas FH \& Vanderhyden BC 2006 Oocyte-granulosa cell interactions during mouse follicular development: regulation of kit ligand expression and its role in oocyte growth. Reproductive Biology and Endocrinology 419.

West MJ 1999 Stereological methods for estimating the total number of neurons and synapses: issues of precision and bias. Trends in Neuroscience 22 51-61.

Wilson T, Wu XY, Juengel JL, Ross IK, Lumsden JM, Lord EA, Dodds KG, Walling GA, Mcewan JC, O'Connell AR et al. 2001 Highly prolific Booroola sheep have a mutation in the intracellular kinase domain of bone morphogenetic protein IB receptor (ALK-6) that is expressed in both oocytes and granulosa cells. Biology of Reproduction 64 1225-1235.

Xia Y, O'Shea T \& McFarlane JR 2003 Concentrations of progesterone follistatin and follicle stimulating hormone in peripheral plasma across the estrous cycle and pregnancy in merino ewes that are homozygous or non carriers of the Booroola gene. Biology of Reproduction 69 1079-1084.

Received 11 May 2009

First decision 8 July 2009

Accepted 8 July 2009 